\title{
On Ghosts and Other Unwelcome Guests
}

\author{
Joseph S. Ross, MD, MHS $1,2,3,4$
}

'Section of General Internal Medicine and the Robert Wood Johnson Foundation Clinical Scholars Program, Department of Internal Medicine, Yale University School of Medicine, New Haven, CT, USA; ${ }^{2}$ Department of Health Policy and Management, Yale University School of Public Health, New Haven, CT, USA; ${ }^{3}$ The Center for Outcomes Research and Evaluation, Yale-New Haven Hospital, New Haven, CT, USA; ${ }^{4}$ Section of General Internal Medicine, Yale University School of Medicine, New Haven, CT, USA.

J Gen Intern Med 30(10):1389-91

DOI: $10.1007 / \mathrm{s} 11606-015-3400-9$

(c) Society of General Internal Medicine 2015

$\mathrm{T}$ en years ago, there were ghosts everywhere in clinical research. There were ghosts writing review articles. There were ghosts writing editorials. And there were ghosts writing articles describing the results of clinical trials. And of course, along with these ghosts, there were many uninvited guests - individuals who were named as authors but who had not contributed substantively to the writing or the design and conduct of the studies.

Ghostwriting is the failure to designate as an author an individual who has made a substantial contribution to the research or writing of a manuscript, ${ }^{1,2}$ such as when manuscripts are prepared by industry representatives on behalf of academics, wherein the role of the company is not disclosed. Guest authorship refers to the designation of an individual as an author who does not meet authorship criteria, ${ }^{1,2}$ for example, when academics are invited to be authors of manuscripts prepared by industry representatives after studies have been completed, crediting the investigator with a role that is not commensurate with their contributions in an attempt to convey academic objectivity. Guest authorship similarly occurs in academic settings, such as when senior academics are named as authors on articles that were written by junior faculty and to which they did not meaningfully contribute. Both practices undermine the integrity of clinical research.

Among journal editors and academics, these ghosts and guests have been widely rumored but rarely discussed, in part because there was no proof of their existence. No one would publicly admit that an article on which they were named as an author was written by someone else, who had not been named as an author. And no one would publicly admit to being a guest author on an article, having contributed little or nothing to the writing or the design, conduct, analysis, or interpretation of the study. However, ghosts and guests also persisted in part because the culture of research accepted, or at least tolerated, these practices. Many academic authors, as well as representatives from industry, believed ghostwriting and guest authorship to be acceptable and mutually beneficial. Academics are

Published online May 19, 2015 promoted and receive recognition on the basis of productivity, so receiving "writing assistance" or being named as an author to a few additional publications was useful for professional advancement. In addition, so long as the academics closely reviewed the article and edited its content to ensure that it reflected their perspectives intellectually, the practice could be rationalized as harmless and justified.

The problem is that authorship in biomedical publications not only provides recognition, but also establishes accountability and responsibility. Key decisions are made during the process of designing and conducting a study and during data analysis and article preparation. Certain issues or findings are prioritized for discussion or given further scrutiny, whereas others are simply not discussed or are even excluded from the publication. Academics who are invited to be guest authors rarely have access to the data for independent analysis, and are only included once the manuscript has first been drafted, after these key decisions regarding presentation of the data have already been made. Ghostwriting goes beyond providing true editorial assistance (i.e., copy-editing), managing references, or table and figure preparation.

Over the past 5 to 10 years, we have finally taken note of these ghosts and unwanted guests. Scandals and litigation have provided heretofore unseen proof of their existence. Litigation related to several pharmaceutical products, including gabapentin (Neurontin), sertraline (Zoloft), conjugated estrogens (Premarin and Prempro), and rofecoxib (Vioxx), ${ }^{3-5}$ provided a unique opportunity whereby court documents could be used to examine the extent of ghostwriting and guest authorship, how these practices were operationalized, and their potential impact on the peer-reviewed biomedical literature. Members of Congress and journalists began their own investigations, leading to front page stories in the New York Times, the Wall Street Journal, and many other newspapers, along with an unprecedented minority staff report from the U.S. Senate Finance Committee led by Senator Charles Grassley.

In response, academic medical centers began establishing formal policies that expressly prohibited ghostwriting and guest authorship, the extent of which is monitored by the American Medical Student Association (AMSA) Scorecard on conflict of interest policies. Similarly, the Pharmaceutical Research and Manufacturers of America (PhRMA), the trade organization representing U.S. pharmaceutical companies, 
updated its voluntary code of conduct to discourage these practices. In addition, the International Committee of Medical Journal Editors (ICMJE) updated its recommendations to define the role of authors and contributors, establishing clear criteria for evaluating authorship. ${ }^{6}$ Moreover, as part of this update, the ICMJE expressly acknowledged that writing assistance can enhance the clinical research dissemination process, and that while medical writers who do not meet the criteria should not be named as authors, they should be acknowledged in the article. ${ }^{6}$

Where does that leave us today? In this issue of the Journal of General Internal Medicine, Roper and Korenstein have attempted to answer that question, ${ }^{7}$ at least with respect to guest authorship. They identified a sample of randomized trials of drugs and devices that were published in highimpact journals in 2012 and that included details on the role of the trial funder/sponsor, provided an explicit statement of authorship contributions, and were registered on ClinicalTrials.gov, a public registry of clinical trials maintained by the National Library of Medicine. Through an examination of published contributions by first and last authors, they determined that $6 \%$ of trials were guest-authored, a number far below prior estimates of approximately $20 \%$ among articles published in the highest-impact general medical journals. ${ }^{8,9}$ However, among trials for which industry provided funding and played a role in their design, conduct, or analysis, $13 \%$ were determined to have been guestauthored, in contrast to none among trials that either did not receive industry funding, or received industry funding but industry played no collaborative role in the trial design or conduct.

With their use of published authorship contributions, Roper and Korenstein should be applauded for their innovative attempt to better understand a problem that is generally known only through anonymous self-report surveys, investigation and discovery, or litigation documents. However, their study was deliberately conservative, categorizing an article as 'not guest-authored' so long as either the first or last author met authorship criteria. But guest authorship by any author, first, last or otherwise, threatens the integrity of clinical research. Moreover, among trials that either did not receive industry funding or received industry funding but industry played no collaborative role in the trial design or conduct, none were determined to have been guest-authored, raising questions about their methods, given the prevalence of this practice in academic settings. ${ }^{10}$ Perhaps authors are applying a lower standard when making statements about authorship contributions, or are falsely inflating their contributions. Furthermore, Roper and Korenstein limited their study to randomized trials published in the highest-impact journals that included statements of funding and authorship contributions and were registered on ClinialTrials.gov. A priori, one would expect that these trials would be among those most likely to be designed and conducted with integrity and to meet ethical standards. Their findings are not generalizable to the many journals that do not provide statements of funding and authorship contributions. Nor are they generalizable to the many observational studies, reviews, meta-analyses, and editorials that populate the pages of the medical literature and are used to inform and influence clinical practice. Finally, it is also important to note that Roper and Korenstein's method could not be used to study ghostwriting, an equally vexing problem for the field.

These limitations suggest that Roper and Korenstein's study should not give a false-sense of 'problem-solved'. Ghosts and unwanted guests continue to haunt the biomedical literature. The steps taken by academic medical centers, PhRMA, the ICMJE and others offer great potential to improve the integrity of clinical research and its dissemination. But more should be done, including clear repercussions for academic authors who continue to utilize ghostwriters and guest author articles, inappropriately taking credit for research in which they did not participate. Biomedical journals might consider retracting these articles, questioning the veracity of their research findings. Clinical research funders, including the National Institutes of Health, might consider permanent or temporary bans on these investigators receiving research support. But at the very least, academic medical centers need to take this information into account when making promotion and leadership decisions. Ghostwriting and guest authorship undermine the integrity of clinical research and should no longer be tolerated.

Conflict of Interest: The author declares that he does not have a conflict of interest.

Funding/support and role of the sponsor: This editorial was not supported by any external grants or funds. Dr. Ross receives research support through Yale University from Medtronic plc and Johnson \& Johnson to develop methods of clinical trial data-sharing, from the Centers for Medicare \&. Medicaid Services (CMS) to develop and maintain performance measures used for public reporting, and from the U.S. Food and Drug Administration (FDA) to develop methods for postmarket surveillance of medical devices, and is also supported by the National Institute on Aging (K08 AG032886) and by the American Federation for Aging Research through the Paul B. Beeson Career Development Award Program.

Corresponding Author: Joseph S. Ross, MD, MHS; Section of Genereal Internal Medicine, Yale University School of Medicine, PO Box 208093, New Haven, CT 06520-8093, USA (e-mail: joseph.ross@yale.edu).

\section{REFERENCES}

1. Rennie D, Flanagin A. Authorship! Authorship! Guests, ghosts, grafters, and the two-sided coin. JAMA. 1994;271(6):469-71.

2. Rennie D, Yank V, Emanuel L. When authorship fails. A proposal to make contributors accountable. JAMA. 1997;278(7):579-85.

3. Healy D, Cattell D. Interface between authorship, industry and science in the domain of therapeutics. Br J Psychiatry. 2003;183:22-7.

4. Ross JS, Hill KP, Egilman DS, Krumholz HM. Guest authorship and ghostwriting in publications related to rofecoxib: a case study of industry documents from rofecoxib litigation. JAMA. 2008;299(15):1800-12.

5. Steinman MA, Bero LA, Chren MM, Landefeld CS. Narrative review: the promotion of gabapentin: an analysis of internal industry documents. Ann Intern Med. 2006;145(4):284-93. 
6. International Committee of Medical Journal Editors. Recommendations for the conduct, reporting, editing and publication of scholary work in medical journals. December 2014; http://www.icmje.org/icmje-recommendations. pdf. Accessed May 1, 2015.

7. Roper N, Korenstein D. Industry collaboration and primary guest authorship of high-impact randomized clinical trials: a cross sectional study. J Gen Intern Med. 2015. doi:10.1007/s11606-0153299-1.
8. Flanagin A, Carey LA, Fontanarosa PB, et al. Prevalence of articles with honorary authors and ghost authors in peer-reviewed medical journals. JAMA. 1998;280(3):222-4.

9. Wislar JS, Flanagin A, Fontanarosa PB, Deangelis CD. Honorary and ghost authorship in high impact biomedical journals: a cross sectional survey. BMJ. 2011;343:d6128.

10. Shapiro DW, Wenger NS, Shapiro MF. The contributions of authors to multiauthored biomedical research papers. JAMA. 1994;271(6):438-42. 